\title{
Informal caregivers who are interested and do make use of information and communication technologies
}

\author{
Gunilla Lindqvist*1, Elizabeth Hanson ${ }^{2,3}$ \\ ${ }^{1}$ Department of Health and Caring Sciences, Linnaeus University, Växjö, Sweden \\ ${ }^{2}$ Department of Health and Caring Sciences, Linnaeus University, Kalmar, Sweden \\ ${ }^{3}$ Swedish Family Care Competence Centre, Linnaeus University, Kalmar, Sweden
}

Received: February 18, 2018

DOI: $10.5430 /$ cns.v6n4p12
Accepted: April 2, 2018

Online Published: April 26, 2018

\begin{abstract}
Objective: The aim of the study was to highlight informal caregivers' interest in using the Information and Communication Technology (ICT)-based ACTION service (Assisting Carers using Telematics Interventions to meet Older People's Needs) and their ideas for how to further develop and extend the service. The use of ICT is constantly increasing worldwide. Europe has the highest old age dependency ratio, but other parts of the world are also experiencing a dramatic ageing of their population. The demands for care are increasing, and resources are shrinking. One way to support informal caregivers is through ICT.

Methods: The study employed a qualitative design. Focus group interviews were carried out with informal caregivers in Sweden. The interviews were analysed using a latent content analysis method.

Results: The analysis yielded a major theme, striving to feel confident, with four categories: informal caregivers' reflections and ideas about ICT; promoting their own health process; increasing their knowledge bank and informal caregivers' rights; and striving for inclusiveness.

Conclusions: The present study highlights the challenges that informal caregivers face in their daily life as well as their resources to devise possible solutions that could improve their situation. To preserve their health, a carer support plan including regular health checks could be helpful. ICT-based support (such as the ACTION service) could act as a way forward for supporting informal caregivers in their striving to feel confident. The study highlighted that ICT-based support has the potential to act as a direct benefit for informal caregivers.
\end{abstract}

Key Words: Informal caregivers, Older people, Information and Communication Technology, Health maintenance, Focus group interviews

\section{INTRODUCTION}

During the first quarter of 2016, 93 percent of all people registered in Sweden had access to the internet at home, corresponding to almost 7 million people. Among older people aged 75-85 years of age, 62 percent, or almost 400,000 private individuals, have access to the Internet at home. ${ }^{[1]}$ The use of Information and Communications Technology (ICT) is constantly increasing worldwide. On average in the EU, 44 percent of those aged 65 to 74 are internet users, while 56 percent do not use the Internet. ${ }^{[2,3]}$ In recent years, Sweden has come slightly further than the United States in the proliferation of computers and mobile phones among seniors when counting everyone over 65 without an upper age limit. ${ }^{[4]}$ Previous empirical studies have revealed that age is not a barrier

\footnotetext{
*Correspondence: Gunilla Lindqvist; Email: gunilla.lindqvist@1nu.se; Address: Department of Health and Caring Sciences, Linnaeus University, Växjö, Sweden.
} 
for the use of ICT. ${ }^{[5-8]}$

Europe is currently the oldest continent in the world with the highest old age dependency ratio and will remain so until 2060. However, other parts of the world are also experiencing a dramatic ageing of their populations, with old-age dependency ratios climbing to levels clearly above the ones in Europe now on all continents except Africa. ${ }^{[9]}$ By 2050, a quarter of the Swedish population will be over 65 years old, and people over 85 will have doubled in number. ${ }^{[9]}$ The labour shortage in healthcare is already a problem, and it is predicted to worsen. ${ }^{[10]}$ In 1970 , Sweden had 25 people of working age per individual older than 80 years. Today, that figure has been halved to 12 , and by 2040 , it is expected to be down 7 persons of working age per person older than 80 years. ${ }^{[11]}$ The demands for care are increasing, and the resources are shrinking, and this has resulted in the need to explore new ways to support carers and their spouses. Given the increasing older population, there are significant opportunities to improve carers' conditions in their everyday life via ICT support. The goal of e-health is to support older people to become independent in their own home, reduce hospitalisations and improve the quality of life for older people and their informal caregivers. ${ }^{[8,12,13]}$

Given the current and future challenges concerning the increasing older population, labour shortages in healthcare and social services, demographic and economic challenges and the possibility to give adequate support to informal caregivers, the use of ICT has the potential to meet and handle this challenge. ${ }^{[14]}$ The use of new technology should no longer be seen merely as "technological development" but as a process that enables and accelerates quality improvement within healthcare and social services in order to better be able to meet individual needs and expectations. ${ }^{[15]}$ Older people who are informal caregivers experience benefits and find ICT useful and worthwhile to use, but it is essential that they are given support and reassurance when they learn to use and continue to use ICT. ${ }^{[5,6]}$ Gender, age, background and education do not seem to have any significance in terms of the ability to absorb or willingness to use technology. ${ }^{[16]}$

\section{Background}

ACTION (Assisting Carers using Telematics Interventions to meet Older people's Needs) is an ICT-based support service that offers support to older people living at home and their carers. ACTION derives from an EU concept and is a support service in community care. ${ }^{[17]}$ The ACTION concept comprises a range of caring educational programmes, video phone applications, communication with other users and ACTION support staff, and a training programme for older people, spousal carers and health and social care staff. ${ }^{[6,12,17]}$

Published by Sciedu Press
Approximately 125 families are currently using the ACTION service in Sweden. In the west of Sweden, where the focus group interviews occurred for the study described in this article, approximately 50 families access the service. Previous studies highlighted that ACTION assisted their wellbeing in a variety of ways. ACTION reduced the sense of isolation and enriched the caring relationship between the frail older person and the spousal carer. ${ }^{[6,12,17]}$ We considered that it was important to re-visit the ACTION service uses in west Sweden and explore their reflections on the service to see whether and how (if any) it had changed their situation. The aim of the study was to highlight informal caregivers' preferences for accessing the ACTION service including their ideas about how to further develop and extend the service.

\section{METHODS}

The study had a qualitative design and employed focus group interviews with a sample of carers using the ICT-based ACTION service. The focus groups were conducted in a social context that allowed the participants to express their experiences and thoughts about ICT. ${ }^{[18]}$ The focus group interviews were analysed using latent content analysis according to methods described by Graneheim and Lundman. ${ }^{[19]}$

\subsection{Participants}

A purposive sample was chosen with regards to the aim of the study. ${ }^{[20]}$ The study included informal caregivers who had experience using the ACTION service. Participants in the first focus group interview were three women and one man. At the second focus group interview, two additional participants, who were both women, took part. On both occasions, two staff members, an ICT coordinator in the municipality who was responsible for the ACTION function together with a prior ACTION coordinator, attended the focus group interviews. They were observers and were responsible for taking notes and tape recording the interview sessions. There were five women and one man aged between seventy-three and eighty-two years old. They had been caring for their spouses between two and sixteen years. Experience with using ACTION varied from one to fifteen years. Three of the caregivers had no prior computer experience when they started using the service. The other three participants had some prior computer experience from their previous jobs so that they were able to surf the internet.

\subsection{Data collection}

An information letter inviting informal caregivers to take part in the two focus group sessions was sent to all registered ACTION users in a municipality in west Sweden. If the carers were interested in taking part in the focus group interviews, they were asked to contact the ICT coordinator 
for more details, and if they wished, they could give their informed consent to participate in the focus group sessions. From the beginning, the plan was to include one staff member who had prior experience with the ACTION service and who now worked with e-learning at the Swedish Family Care Competence Centre. However, on the day of the sessions, the current ICT coordinator also attended the session and wanted to "sit in" and listen to the discussions. Data collection occurred on two occasions between March and April 2015 through focus group interviews. ${ }^{[21]}$ The interviews occurred in a conference room at a senior centre. The first focus group interview occurred between 12:00 to 15:00, and the second one between 10:00 to 14:00; the interviews included a break for refreshments and lunch and short pauses to "stretch the legs". Data collection was based on semi-structured interview guides consisting of open-ended questions. ${ }^{[19,22]}$ The interviews were conducted by a moderator (first author) who facilitated the discussion. The former staff member was an observer who was responsible for notes and tape recording the interview sessions. The audiotaped interviews were transcribed verbatim. The moderator described the aim of the study and encouraged the participants to talk spontaneously. The moderator supervised the group interactions. The partic- ipants were so engaged in the conversation that sometimes they talked in unison. The moderator had to remind them to talk individually several times. After the interviews, the moderator and the observer summarised the interviews.

\subsection{Data analysis}

Qualitative content analysis, as described by Graneheim and Lundman, ${ }^{[19]}$ was used in order to uncover the latent content and underlying meaning in the text. An inductive approach was chosen as a means to achieve an unprejudiced analysis of the texts based on the carers' narratives about their experiences. The analysis was performed in several steps. The text was read several times to gain an understanding and to reflect on the content of all of the data. Based on the study aims, each interview text was divided into meaning units, each comprised of numerous words and sentences containing parts related to each other through their content. The meaning units were condensed into shorter sentences, i.e., condensed meaning units. The condensed meaning units were then labelled with a code. The various codes were then compared and, depending on their content, organised into subcategories. These subcategories were then related to four categories (see Table 1). ${ }^{[19,21]}$

Table 1. Example of the process of analysis

\begin{tabular}{lllll}
\hline Condensed meaning unit & Code & Subcategory & Category & Theme \\
\hline $\begin{array}{l}\text { Only after my husband died I contacted a } \\
\text { doctor because of high blood pressure }\end{array}$ & Need physician & Having access to health & Promoting their own & Striving to feel \\
contact & hecks, and relief & health process & confident \\
$\begin{array}{l}\text { You are alone and there are times where it } \\
\text { is monotonous and you feel isolated }\end{array}$ & $\begin{array}{l}\text { Need support to } \\
\text { break the isolation }\end{array}$ & $\begin{array}{l}\text { Getting support to enrich } \\
\text { and break the isolation }\end{array}$ & $\begin{array}{l}\text { Striving for } \\
\text { inclusiveness }\end{array}$ \\
\hline
\end{tabular}

\subsection{Ethical considerations}

The principles outlined in the Declaration of Helsinki ${ }^{[23]}$ and the Swedish ethical review act concerning research that involves humans ${ }^{[24]}$ have been followed throughout the study. The study was approved by the regional ethical board at the University of Gothenburg (number 370-11). The participants received oral and written information about the aim of the study. They were also informed about the voluntary nature of their participation and their right to withdraw at any time without any consequences. All participants were assured of confidentiality and anonymity in the presentation of the study.

\section{RESULTS}

The findings are presented in one overall theme of striving to feel confident and four categories: carers' reflections and ideas of ICT, promoting their own health process, increasing their knowledge bank and carers' rights, and striving for inclusiveness, as well as their subcategories (see Figure 1).

\subsection{Striving to feel confident}

Informal caregivers expressed that initially they had not been afraid of using the ACTION service because they felt confident in the knowledge that support was available via the videophone with the ICT coordinator. Overall, participants used the service frequently, and they had numerous ideas about how to improve ACTION. By contrast, the participants expressed that they did not receive the support they needed from the municipality and county council; therefore, they were interested to learn about their legal rights. The caregivers' own perceived health status and access to support was an important aspect concerning the length of time they had been caring for their spouse/partner. The caregivers expressed that their overall goal in using the service was to feel confident in their caring situation. 


\section{Striving to feel confident}

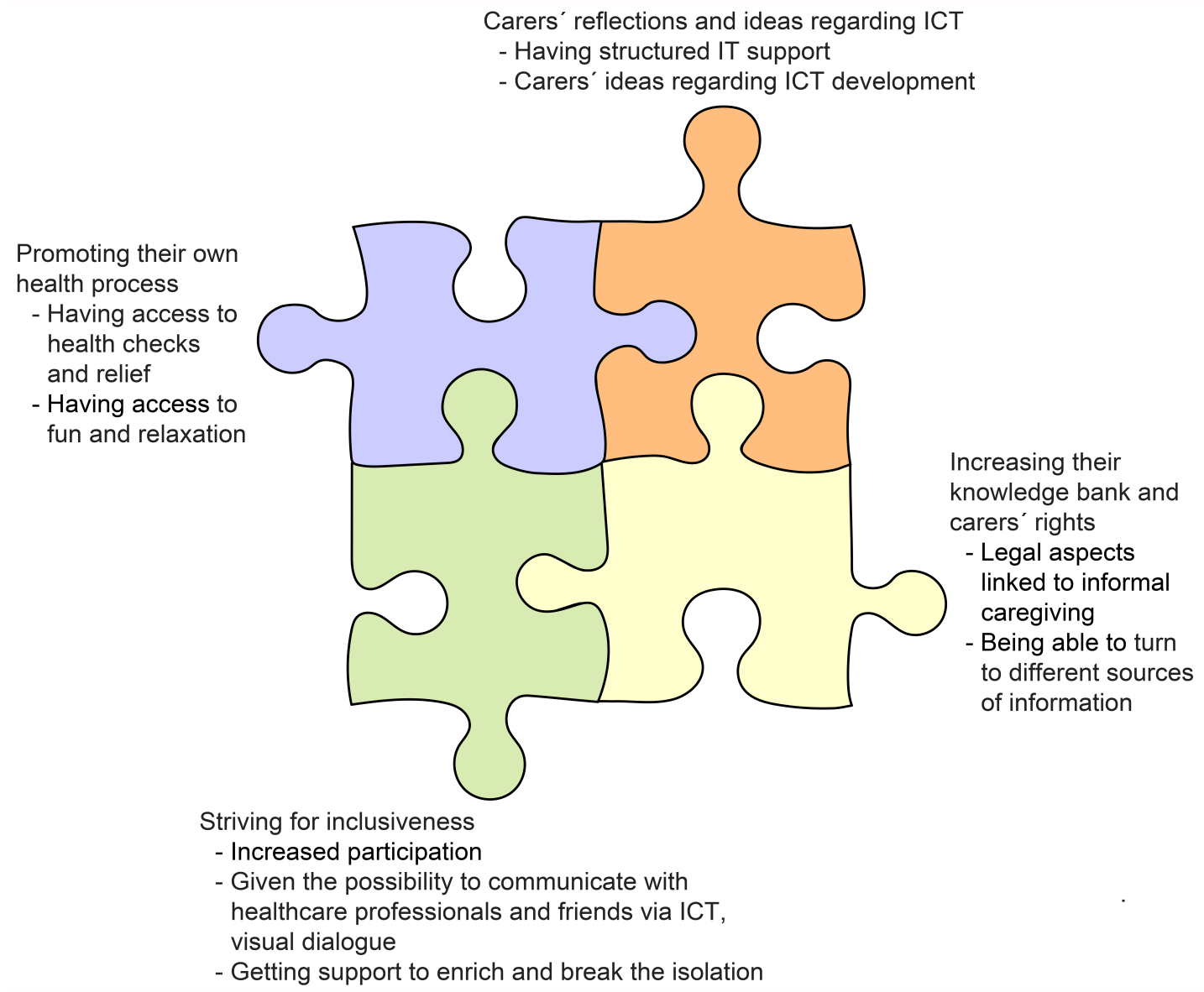

Figure 1. Striving to feel confident

\subsubsection{Informal caregivers' reflections and ideas regarding ICT}

The first category described how important it is to have structured ICT support and to have an ICT coordinator the participants could ask questions of when they had problems with the ACTION service. Participants had various ideas for how the service could be further developed to meet carers' needs and preferences.

(1) Having structured IT support

Contact with the ICT coordinator who was also a family care support worker was extremely important for the participants. They felt that it was possible to use the computer when they had support from the ICT coordinator. They experienced that they could ask all kinds of questions in order to enable them to continue to use the computer; no question was stupid. The ICT coordinator could also remotely control their computer, which was very helpful because the problems could be solved simply. They felt confidence in the ICT coordinator, equal to a spouse supporter, with whom they could discuss their problems; they also knew there was someone they could contact directly who knew them and their difficulties in their daily life as informal caregivers. It felt good for the users when they turned on the computer and they had a welcome message on the computer screen. The ACTION tool did not make participants feel afraid of computers; instead, it was a tool to facilitate their everyday lives.

"I turn off my computer every night and then press it on in the morning, and just the greeting that you get there is so fine." (2)

(2) Informal caregivers' ideas on ICT development

Participants had various ideas about how the ICT "ACTION" tool could be further developed to meet carers' needs. It is important that the information can be easily found and that the information is updated regularly. The pages should be logically structured via different themes that can be clicked on according to the particular interests or situation of the caregiver. It should be easy to find on the home page. Some of the participants made use of Facebook and thought it 
would be good to get into a similar flow of information in the ACTION system, where they would be able to write status updates. As an ACTION user, it should be possible to add messages and type on Facebook. They admitted that it would be beneficial if a mail function could be added.

"Mail would be great for that is what you do." (5)

There was a desire that some of the contact with healthcare professionals could sometimes be operated through video contact as trips to healthcare facilities could be tiresome both for the patient themselves but also for the carers. It was important for the informal caregivers to see the other person not only by the phone. All were united that one does not want to call 112 (911) if there was an emergency because they did not want to burden this number. Instead, they wanted to have a phone list in which all the important phone numbers were posted, for example, police, ambulance, healthcare, municipalities, utilities, and needs assessor. Participants wanted to find emergency phone numbers quickly, and they wished to be able to reach appropriate emergency services when an urgent situation arose.

"So many people are afraid today; there are an awful lot of people who are not nice to us when we get older, but where do I call? You cannot even look in a telephone directory." (4)

Participants had suggestions about creating a sponsorship where experienced ACTION users become a "godparent" to novice users. Some of the participants suggested that carers themselves could become a "fellow human being" or mentor for another novice carer who was in need of support and that this could be added into the system so that the contact could be created in the ACTION catalogue system. Further, they stated that even volunteers in the community who wished to become a mentor to an informal caregiver could be added into the system. Some suggested that carers could be connected to a nursing home when they needed support, at least at night.

The participants wanted to have a message function in ACTION where members could easily send out a message, for example, to debate issues. The function could also be used, e.g., at night when they were in need of someone to talk to, and with the message function, the user could easily see if anyone else within the ACTION caring community were online. They also suggested that the message function could be used when carers want to ask a question about something. There would be a tab, a so-called suggestion box, so that the ACTION users could come up with ideas for further developing ACTION. The participants wanted to have linked information relating to carers, e.g., research papers or news from different sources.
"When you read the information about the disease and you have questions, it is very difficult to get in touch by videophone at once but through message and possibly later by a videophone call." (1)

Some of the participants confided that their new life situation as carers did not match with the lives of their old friends because they were often forced to live a different life, and they expressed that in this session, the ACTION service had become a sort of rescue. This led to carers feeling more acknowledged; they could accept their situation in a better way. Their experience with their situation as informal caregivers was facilitated, and they got more strength from it. Participants suggested that a presentation of the ACTION service to new users would be beneficial, as they considered that it would create a social community where common interests were acknowledged and shared. Participants admitted that it was important to get training in the ICT services, which then also acted as a means to build up a social network with other carers in a similar situation to their own. They argued that the social network could ultimately also involve connections across municipal boundaries through the integrated videophone feature.

"ACTION has given me a sense of security and new social contacts; you feel you are in the same boat, and then you can talk to someone from another municipality too." (6)

Participants were appreciative of being able to take advantage of the technical possibilities that were provided because they enabled them to become part of the current information society. They recognised that the current generation uses ICTs, and in the future, they recognised that the computer literate generation will be able to take even more advantage of modern technology. The ACTION service was regarded as a valuable assistive tool in the informal caregiving process of an older spouse. Nevertheless, several caregivers considered that the costs for the service were too high.

\subsubsection{Promoting their own health process}

Participant caregivers were aware that they had a huge responsibility for and played an important role for their spouses. Nevertheless, at the same time, they expressed that they did not feel that they were taken sufficiently seriously enough either by the municipality or county council. Caregivers admitted that when they felt good about themselves and their situation, it tended to reflect directly on their spouse's wellbeing. When the participants' responsibility for their spouse increased, the focus on their own needs and health and wellbeing tended to decrease. Participants felt that outside the ACTION service, there was no one who observed or took care of the carers' health. Rather, the caregivers felt that it was taken for granted by society that they would care for

ISSN 2324-7940 E-ISSN 2324-7959 
their spouses at home. The participants felt that they did not get the support they needed from the municipality and county council, resulting in their being exposed to ill health and a lack of wellbeing. To preserve their health, the informal caregivers needed support, access to relief and some fun and relaxation.

(1) Having access to health checks and access to relief

The caregiving situation was distressing many times, and it brought consequences on their health both physically and mentally. Their daily life was limited and restricted because it was difficult to leave their sick spouses. The participants expressed that they were under huge pressure all the time. Some of the participants wrote on patches to remember all of the things they would do and continually pondered them in things that would be executed. The participants were constantly worried about if they got sick and what would occur to their spouses then. Therefore, they wish to receive a health check once a year. The support from ACTION positively affected the quality of life of the participants, resulting in increased well-being and security. Being able to influence and participate in their own life situation was strongly linked to how they felt physically and mentally.

It was difficult to relax, resulting in disturbed sleep both depending on plundering but also disturbed sleep from their spouse. Fatigue was described as intense, like a hood on the head. The normal couple relationship ended because the participants had to take on the role of a caregiver. With some diseases, a personality change followed that carers also had to address; personality changes also lead to grief. Participants were frustrated that support was often absent and that the work they performed was not valued by the municipality and the county council. Their view was that the municipality saved money at their expense.

" $X X X$, he receives the annual inspections, his values are good, as a relative then you are tired, nervous, anxious; there is no one who really cares about us... you feel as an employee in every way. What if someone asked if you have any control? You do not think of it yourself, one morning I could not go out of bed, I could not stand on my feet." (5)

\section{(2) Having access to fun and relaxation}

The participants could be relieved from their caring responsibilities on the occasions when their spouse sat and played games via ACTION. In some cases, carers explained that the games become an interesting activity for both the carer and the spouse as a couple. When the participants felt tired and down, they explained that ACTION was a source of support in terms of slideshows and games such as Spider Solitaire, and patience, which brought relaxation to their daily life.
Participants acknowledged that the ACTION service constituted a large part of their social life, easing the loneliness and isolation of their situation. Caregivers acknowledged that ACTION helped them to manage by listening to music, reading, and yoga and by being able to converse with other carers in a similar situation to their own.

“...The body reacts; it would certainly put a stop to our part unless it had had something that weighed it up a little bit and it was through ACTION, and in that, I could not go out at all." (2)

They felt mentally leached, and there were concerns about how long they would be able to continue caring for their spouses. The emotional support via ACTION, from both peers and professionals, was deemed to be important. For example, to be able to talk to someone when the caring duties became too heavy, such as at times of mental distress, a crisis or following the death of their spouse to help with the immediate post-bereavement process, helped them to get through. Participants spoke of an emotional stress that was present and how these emotions became heightened during the night time. ACTION support was only available during the day, but the participants' expressed the need for further support at night. They expressed the need for someone understanding to recognise their needs, both physical and mental. They suggested that the need to be in contact with someone at night when the anxiety came could be linked via the ACTION service to staff at the local nursing home.

"It would be great if there was someone you could talk to when you wake up at night and are heartbroken; it is important, for it always happens at night, everything ... well any care personnel, you feel so alone." (3)

The participants explained that they sought happier and lighter sides for the soul in ACTION such as video clips, music elements such as classical or soft music, culture, and something to laugh about, e.g., sketches, funny stories and fun games.

\subsubsection{Increasing their knowledge bank and carers' rights}

As an informal caregiver for their loved ones at home, they needed information and support. The ACTION service was a valuable source of information for them. By gathering information that gave them knowledge, they felt that they could continue to care for their spouses at home.

"It has all the information, that is how I see the computer; it is like an information source." (5)

(1) Legal aspects linked to informal caregiving

Participants sought information about caregivers' rights; there was uncertainty as to what rights they had. When 
the caring duties became too heavy for them, they needed information and support for locating respite care for their spouse, so that they could rest for a while. They acknowledged that it was currently nearly unfeasible for this to occur. This is because the short-term care places are too few.

They also had concerns about legal issues relating to caregiving, and they expressed an interest to be able to stay online and have a videophone conversation with a lawyer, for example, to discuss legal issues affecting older people's situations such as division of property, inheritance, what to do if they have a car that they cannot take care of, how to close bank accounts, the financial wellbeing of the surviving spouse and her/his financial situation. The informants also requested information about what rights they had in relation to health and care services and what they could reasonably request.

"The legal aspects need to appear also, inheritance issues and how to handle the situation when your loved one dies." "Being able to turn to different sources of information." (5)

The participants said that they were in need of information to feel more secure in their role as informal caregivers. Participants' sense of a lack of knowledge was eased because they could read information about their spouses' diseases.

ACTION gave them, to some extent, more knowledge; however, they felt that they could gain even more in-depth knowledge. The participants were keen to learn more about the disease. To be able to feel safe while caring for their spouse, they argued that they should have the opportunity to gain skills to cope with their caring situation. They explained that when their spouses' health deteriorated, the demands on them changed, and they needed time to gain new knowledge and caring skills. Via accessing information through the ACTION service, they explained that it gave them support and helped to ease their stress because they felt they were able to provide safer and better care for their spouse.

"It is important for caregivers to know more about the disease; you do not know, you have no training, you become really worried. When you know, for example, about stroke then you can handle it." (2)

The information in the ACTION service gave the participants the opportunity to receive information on assistive devices that they could benefit from and to make an application for benefits.

\subsubsection{Striving for inclusiveness}

Caregivers experienced a constant struggle to get support from the county council and municipality, and they were questioned repeatedly if the requirements they demanded were necessary. Participants put forth effort to reach differ- ent people within the municipality and county council to get answers to their questions as well as support. This took both power and energy from them; time was spent sitting by the phone instead of giving care to their spouses. Being able to influence their spouses' health was strongly linked to how they felt physically and mentally. Their idea was that if they could come into contact with doctors and nurses via ACTION, video phone would greatly improve their situation.

Participants gained strength from the social support networks that were established via their contacts with other ACTION users. They were able to seek and gain advice from others in a similar situation to their own. Via ACTION, they accessed pictures and games and connected with other informal caregivers and their own family.

"It means a lot; we talk to each other, someone who has the same situation as me, and we gave each other advice and help each other." (3)

Their contact with health services (when they visited healthcare professionals with their spouse) was improved because as a result of using the ACTION service, they had gained more knowledge of their spouse's illness and could ask questions.

"I could support my husband mentally when he had depression, so when he was feeling good, I felt good... it meant a lot to me that I could take part in the various parts of the ACTION service." (1)

\section{(1) To allow increased participation}

The carers expressed needs of communication, learning and social relationships for participation, and it can be seen that via the ICT-based service, the informal caregivers had access to all of these aspects at least to some degree. ACTION users experienced greater participation by contact with others. However, they expressed that the missing piece within the ACTION service was direct contact with the healthcare staff in primary healthcare and at the hospital. The main thing was that they got the help and guidance they needed. Participants felt that there was a gap between the county and municipality with regards to good cooperation.

There was no cooperation in the support of informal caregivers between the municipality and healthcare; from the participants' point of view, it was considered as non-existent. Participants felt that they got mixed messages from the municipality, county council and medical centre. Cross-border cooperation would have been desirable for supporting the carers where ACTION could be a solution they suggested.

"It feels like it is two rivals as well... it is healthcare... They are involved; they should have the same record and same 
system.” (5)

It was of great importance to have good communication with healthcare professionals, to be listened to and be seen as a person, knowing that their knowledge and experience was sought after by the healthcare professionals. However, this was not the case for the majority of the participants. They wanted to be listened to, to be trusted and to be seen as a person; additionally, they wanted their knowledge and experience to be requested by healthcare professionals.

(2) Given the possibility to communicate with healthcare professionals and friends through ICT, visual dialogue

The freedom and spontaneity of the participants' daily life disappeared, and they were often housebound because they had difficulty leaving their spouses without supervision. This limitation reduced their quality of life. By using ICT (ACTION), they expressed that their quality of life had improved. They noted that in many cases, their old friends had disappeared, and yet, they had made new friends via the videophone (visual dialogue). Informal caregivers who had shown signs of despair and weakness had been caught up by conversation, guidance, advice and support from other ACTION caregivers in a similar situation to their own so that they tried to stay on top of things.

"Action has been everything to me, the caregiver support; I had not managed it (caring situation) otherwise, it gave security." (2)

\section{(3) Getting support to enrich and break the isolation}

To care for their spouses meant that they had to give up many of their former interests and activities, and they felt confined to the four walls of their home. Their caregiving duties were sometimes extremely time-consuming and strenuous and, in some cases, involved caring for the spouse around the clock. Several of the caregivers received appreciation from their spouses, but not all, depending on whether their spouse's personality had changed depending on the disease. The caregivers' sense of isolation had an impact on their social networks; friends had disappeared, and a sense of loneliness appeared. The ACTION tool supported them to overcome isolation and loneliness and to reach out to others.

\section{Discussion}

\subsection{Discussion of the findings}

This study shows the benefits that the informal caregivers received from the use of an ICT-based service, ACTION. Assisting informal caregivers using telematic intervention to meet older person's needs (ACTION) is highlighted on an EU level as being a useful tool. ${ }^{[14]}$ There is a growing indication that technology, such as telecare and telehealth,

Published by Sciedu Press supports both the patients and their informal caregivers and other relatives. ${ }^{[7,13,14,25,26]}$ This study provides insights into what is important in their role as carers and, furthermore, their experience of using ICT. The findings show that age is not an obstacle to using ICT among carers; they observed it as a tool they could benefit from in their daily life as caregivers. This is in line with other studies that show that age is not a barrier to using ICT. ${ }^{[5,8,13]}$ What, on the other hand, is important, as this study shows, is that the carers have structured ICT support and that they are involved as users so that modern information technology is able to meet their needs by creating it to be something they want, need and see the point of using.

The older population will increase by 30 percent between 2010-2050 in Sweden; ${ }^{[27]}$ an increasing population of older people is also the case for other countries. The demand for informal care will likely grow significantly. According to Berglund et al., ${ }^{[28]}$ this will be an increasing problem for society, as it is increasingly depending on informal caregivers to provide help, support and even care to their aged relatives on a regular basis. Therefore, ICT-based support can be a valuable complement in the future, as suggested by previous studies. $^{[8,12,13]}$

Informal caregiving is one of the oldest types of care systems, and it seems that this will not change in the future. Because of the continued emphasis on community care policies and economic cutbacks as well as a constant decrease in the number of nursing home beds, an increasing number of old people will be cared for by informal caregivers in their home. ${ }^{[29,30]}$ Society often takes for granted that relatives care for their spouses at home as demonstrated in the study by Horrell et al. ${ }^{[31]}$ They also note that because the family structure has changed, it becomes more problematic; women are working, and the opportunity and the willingness to be a carer have changed. Several of the participants felt that they did not receive the support they needed from the municipality or county council, and they were left alone with heavy caring responsibilities. The municipality and county council have to prepare for the changes that happen, and it is not a matter of course that generations in the future will want to be family carers, especially if they do not receive support.

Caring for a prolonged length of time does have consequences for informal caregivers' own mental health and wellbeing. ${ }^{[28,32-36]}$ Similar to previous studies, this study shows that caregivers are at risk of physical and mental ill health if they do not receive support from the municipality and county council. This in contrast to a study by Gautun et al., ${ }^{[37]}$ where only a few informal caregivers indicated worsened health resulting from caregiving duties. Fagerstrom et 
al. ${ }^{[38]}$ argued that the use of ICT in health service settings can allow patients and their informal caregivers to communicate with their care manger when face-to face contact is not possible. However, they noted that the ICT cannot replace personal attendance. The present study shows that ICT-based support such as the ACTION service can support informal caregivers to become as independent as possible and can help them to improve their well-being, which is consistent with previous studies. $^{[12,13,39]}$

The caregivers needed support and access to relief but also to have some enjoyment in their daily life. The informal caregivers have to deal with many caring responsibilities and constantly live with the feeling that they are not enough; therefore, ACTION was a source of enjoyment and relief for both the informal caregivers and their spouses.

It is important that support is given in terms of the physical and mental consequences to which they are exposed. Therefore, it could be beneficial for informal caregivers to be offered regular health checks and a carer support plan where healthcare professionals coordinate necessary support. ${ }^{[28,34,35]}$ This professional coordinator could, for example, be a contact nurse or informal caregiver advisor/advocate in the municipality who can follow up on the issues that arise in connection with informal caregiving. The contact nurse or caregiver advisor/advocate follows up with the carer support plan and ensures that time is given for regular health checkups for the informal caregiver. One can argue that because of the current financial climate, this is not realistic. However, approximately 1.3 million Swedish people care for a close relative, which means a savings of 22.3 billion dollars for society. ${ }^{[40]}$ This was also shown in a dissertation written by Sjölander, ${ }^{[41]}$ where it was found that informal caregivers saved money for society with their efforts to care for their relatives. If the home service performed the same efforts, it would have cost the community 37,603 dollars per patient over a 15-month period. More attention should be drawn to informal caregivers; unless this is done, they risk being tomorrow's patients.

The present study reveals that the participants were uncertain about what rights they were entitled to as informal caregivers. They were often ill-informed by the healthcare sector and the municipality about what rights they had in relation to their caring situation, as well as regarding legal issues. Through ICT (ACTION), various professionals and officers such as lawyers, bank staff, municipality officials, and healthcare contact persons should be available via the videophone, so that informal caregivers can secure the specific tailored information and advice that they request. The use of ICT can be effective, low-cost and an important personal support tool for informal caregivers; this has also been confirmed by other studies. ${ }^{[6,7,9,39]}$

\subsection{Methodological discussion}

The strength of the study is that the informal caregivers who had experience using ICT were given the opportunity to describe and discuss their experiences and reflections about ICT-based support services. Focus group interviews were the natural choice of this study because interviews permit data both from the individual and from the individual as part of a larger group. Furthermore, focus group discussions are considered to be the method of choice for exploring opinions, views, and attitudes regarding a certain area in an interactive situation. ${ }^{[21]}$ The participants were so engaged in the conversation that they sometimes talked in unison, creating some problems when the data were transcribed verbatim. Nevertheless, this highlighted that their thoughts and ideas flowed. A further strength of the study is that data collection occurred on two occasions, giving participants some time to reflect after the initial session and prior to the second session taking place.

A limitation of this study is that participants self-selected to take part; therefore, it can be argued that those who participated were more positive and that the views perhaps of more critical or non-users are missing. Another limitation is the small number of interviews that were conducted; for that reason, further studies are warranted. A further limitation is that there was only one male participant.

Several steps were taken to increase the trustworthiness of the study. To assure trustworthiness, the criteria mentioned by Graneheim and Lundman ${ }^{[19]}$ containing credibility, dependability and transferability were carefully followed. The interviewer (i.e., the first author) strived to be conscious of preconceptions as a nurse. To ensure transparency of the analysis, efforts were made to select representative quotations, to provide the reader with an opportunity to evaluate the interpretation as well as its relevance to similar settings.

\section{Conclusions}

The present study highlights the challenges that informal caregivers face in their daily lives but also their strengths in coming up with ideas that could improve their situation. To be an informal caregiver creates consequences of physical and psychological strain. By introducing a spouse plan or caring model, healthcare has the opportunity to follow the caregivers' ideas and needs to take care of their spouses at home. To preserve their health, carers should be offered regular health checks, and the community municipality can offer opportunities for fun and relaxation. ICT and ACTION could be a way to give support to informal caregivers so 
that they feel confident and confirmed in their new role as informal caregiver. However, when ICT is introduced, it is very important that they have structured IT support. There is also a need to increase informal caregivers' knowledge bank and their legal rights; this is possible via ACTION and videophone. This study showed that ICT-based support for informal caregivers can work well and is of great benefit; caregivers are not afraid to use it if they have IT support. The study also shows that the informal caregivers had several concrete ideas about how to further develop the service, namely, contact with healthcare professionals could sometimes be operated through video, and linked information relating to carers, e.g., research papers or news could be provided; message functionality could also be used when carers want to ask a question, and a suggestion box could be added so that users could come up with ideas for further developing ACTION.

\section{ACKNOWLEDgements}

The authors want to thank the participants for sharing their experiences.

\section{CONFlicts OF INTEREST Disclosure}

The authors declare they have no conflicts of interest.

\section{REFERENCES}

[1] Statistics Sweden. Use of computers and the internet by private persons in 2016. Stockholm; 2006 [cited 2016 Mar 18]. Available from: http://www.scb.se

[2] Findahl O. Pensionärerna och internet 2014. Stiftelsen för internetinfrastruktur [Pensioners and the internet 2014. Internet infrastructure foundation]. 2014 [cited 2016 Mar 18]. Available from: www. poi2014.se

[3] Eurostat. Individuals - internet use. 2015

[4] Smith A. Older adults and technology use. Pew Research Internet Project. 2014.

[5] Magnusson L, Hanson E, Borg M. A literature review study of information and communication technology as a support for frail older people living at home and their family carers. Technol Disabil. 2004; 16: $223-235$

[6] Magnusson L, Hanson E. Supporting frail older people and their family carers at home using information and communication technology: cost analysis. J Adv Nurs. 2005; 51: 645-657. PMid: 16129015. https://doi.org/10.1111/j.1365-2648.2005.03541.x

[7] Hanson E, Magnusson L, Arvidsson H, et al. Working together with persons with early stage dementia and their family members to design a user-friendly technology-based support service. Dementia. 2007; 6: 411-434. https://doi.org/10.1177/1471301207081572

[8] Blusi M, Asplund K, Jong M. Older family carers in rural areas: experiences from using caregiver support services based on Information and Communication Technology (ICT). Eur J Ageing. 2013; 10: 191-199. PMid: 28804294. https://doi.org/10.1007/s10433 -013-0260-1

[9] European Commission. The 2015 ageing report: underlying assumptions and projection methodologies. European Economy 8/2014. 2014 [cited 2016 Mar 9]. Available from: http://ec.europa.eu/economy_finance/publications/ European_economy/2014/pdf/ee8_en.pdf

[10] Liu JX, Goryakin Y, Maeda A, et al. Global health workforce labor market projections for 2030. Hum Resour Health. 2017; 15: 11. PMid: 28159017. https://doi.org/10.1186/s12960-017-0187-2

[11] Thorslund M. Han bryr sig om de allra äldsta [He cares about the oldest ones]. Medicinsk Vetenskap. 2012; 3.

[12] Magnusson L, Hanson E. Partnership working: the key to the ATtechnology transfer process of the ACTION service. Technol Disabil. 2012; 24: 219-232.

[13] Carretero S, Stewart J, Centeno C. Information and communication technologies for informal carers and paid assistants: benefits from micro-, meso-, and macro-levels. Eur J Ageing. 2015; 12: 163-173. PMid: 26346568. https://doi.org/10.1007/s10433-015-0 333-4

[14] European Commission. Mapping of effective technology-based services for independent living for older people at home. Seville: Joint Research Center, Institute for Prospective Technological Studies, JRC Scientific and Technical Reports Series; 2015.

[15] Ministry of Health and Social Affairs. National eHealth- the strategy for accessible and secure information in health and social care. 2011 [cited 2016 Mar 16]. Available from: www. sweden.gov. se/ehea lth

[16] Hjälpmedelsinstitutet. Swedish institute for assistive technology. Hemma Med IT. Slutrapport. At Home with IT. Final Report. 2009 [cited 2015 Mar 9]. Available from: www.hi.se/publicerat

[17] Magnusson L, Hanson E, Nolan M. Assisting carers using the ACTION model for working with family carers. Br J Nurs. 2002; 11 : 759-763. PMid: 12070378. https://doi.org/10.12968/bjon. 2002.11.11.759

[18] Hennink MM. Focus group discussions-understanding qualitative research. New York, NY: Oxford University Press; 2014. https://do i.org/10.1093/acprof : osobl/9780199856169.001.0001

[19] Graneheim UH, Lundman B. Qualitative content analysis in nursing research: concepts, procedures and measures to achieve trustworthiness. Nurse Educ Today. 2004; 24: 105-112. PMid: 14769454. https://doi.org/10.1016/j.nedt.2003.10.001

[20] Patton MQ. Qualitative research and evaluation methods. 3rd ed London, UK: Sage; 2002.

[21] Krueger RA, Casey MA. Focus groups: a practical guide for applied research. Thousand Oaks, CA: Sage; 2009.

[22] Lundman B, Graneheim HU. Kvalitativ innehållsanalys [Qualitative content analysis]. In: Granskär IM, Höglund-Nielsen B, editors Tillämpad forskning inom hälso-och sjukvård. Lund: Studentlitteratur; 2008. 159-172 p.

[23] World Medical Association (WMA). Declaration of Helsinki - ethical principles for medical research involving human subjects. 2013 [cited 2015 Feb 12]. Available from: http://www. wma.net/en/3 Opublications/10policies/b3/

[24] SFS2003:460. Lag (2003:460) om etikprövning av forskning som avser människor. 2003 [cited 2015 Feb 12]. Available from: http://www.riksdagen.se/svDokument-Lagar/Lagar/Sve nskforfattningssamling/Lag-2003460-om-etikprovnin g-_sfs-2003-460 
[25] Hanson E, Magnusson L, Sennemark E. Blended learning networks supported by information and communication technology: an intervention for knowledge transformation within family care of older people. Gerontologist. 2011; 51: 561-570. PMid: 21398383. https://doi.org/10.1093/geront/gnr015

[26] Lindqvist GE, Hanson E. Conceptions of everyday life among people living alone with chronic obstructive pulmonary disease. Clin Nurs Stud. 2016; 4: 8-20. https://doi.org/10.5430/cns.v4n2p8

[27] SCB. Befolkningspyramiden har blivit ett torn [The population pyramid has become a tower]. 2014 [cited 2016 Nov 5]. Avail able from: http://www.scb.se/sv_/Hitta-statistik/Art iklar/Befolkningspyramiden-har-blivit-ett-torn/

[28] Berglund E, Lytsy P, Westerling R. Health and wellbeing in informal caregivers and non-caregivers: a comparative cross-sectional study of the Swedish general population. Health Qual Life Outcomes. 2015; 13: 109. PMid: 26216099. https://doi.org/10.1186/s12955 -015-0309-2

[29] NBHWS. Anhöriga som ger omsorg till närstående [Family carers who gives care and support to family members]. Sweden: Socialstyrelsen (National Board of Health and Welfare Sweden); 2012.

[30] Andersson S, Magnusson L, Hanson E. The use of information and communication technologies to support working carers of older people - a qualitative secondary analysis. Int J Older People Nurs. 2016; 11: 32-43. PMid: 26073289. https://doi.org/10.1111/opn. 12087

[31] Horrell B, Stephens C, Breheny M. Capability to care: supporting the health of informal caregivers for older people. Health Psychol. 2015; 34: 339-348. PMid: 25110849. https ://doi.org/10.103 $7 /$ hea0000144

[32] Neri AL, Yassuda MS, Fortes-Burgos AC, et al. Relationships between gender, age, family conditions, physical and mental health, and social isolation of elderly caregivers. Int Psychogeriatr. 2012; 24: 472-483. PMid: 21929829. https ://doi.org/10.1017/S10416 10211001700
[33] Yeh PM, Bull M. Use of the resiliency model of family stress, adjustment and adaptation in the analysis of family caregiver reaction among families of older people with congestive heart failure. Int J Older People Nurs. 2012; 7: 117-126. PMid: 21631886. https ://doi .org/10.1111/j.1748-3743.2011.00275.x

[34] Lindqvist G, Albin B, Heikkila K, et al. Conceptions of daily life in women living with a man suffering from chronic obstructive pulmonary disease. Prim Health Care Res Dev. 2013; 14: 40-51. PMid: 22785223. https://doi.org/10.1017/S146342361200031X

[35] Lindqvist G, Heikkila K, Albin B, et al. Conceptions of daily life in men living with a woman suffering from chronic obstructive pulmonary disease. Prim Health Care Res Dev. 2013; 14: 140-150. PMid: 23026500. https://doi.org/10.1017/S1463423612000394

[36] Limpawattana P, Theeranut A, Chindaprasirt J, et al. Caregivers burden of older adults with chronic illnesses in the community: a cross-sectional study. J Community Health. 2013; 38: 40-45. PMid: 22689437. https://doi.org/10.1007/s10900-012-9576-6

[37] Gautun H, Werner A, Luras H. Care challenges for informal caregivers of chronically ill lung patients: results from a questionnaire survey. Scand J Public Health. 2012; 40: 18-24. PMid: 22006166. https://doi.org/10.1177/1403494811425712

[38] Fagerstrom C, Tuvesson H, Axelsson L, et al. The role of ICT in nursing practice: an integrative literature review of the Swedish context. Scand J Caring Sci. 2017; 31: 434-448. PMid: 27507258. https://doi.org/10.1111/scs. 12370

[39] Schmidt A, Chiatti C, Fry G, et al. Analysis and mapping of 52 ICT-based initiatives for caregivers: deliverable 2.3. Vienna: European Commission, Joint Research Centre, Institute for Prospective Technological Studies Web; 2013.

[40] The Swedish Family Care Competence Centre (SFCCC). 2017 [cited 2017 Dec 6]. Available from: http://www . anhoriga.se/nyhete r/vardet-for-anhorigvard-181-miljarder-kronor/

[41] Sjölander C. Consequences for family members of being informal caregivers to a person with advanced cancer [doctoral dissertation]. Jönköping: Högskolan Jönköping; 2012. 